\title{
Induced Abortion in Tehran, Iran: Estimated Rates and Correlates
}

By Amir Erfani

Amir Erfani is assistant professor,

Department of Sociology, Nipissing University, North Bay, Ontario, Canada.

CONTEXT: Abortion is severely restricted in Iran, and many women with an unwanted pregnancy resort to clandestine, unsafe abortions. Accurate information on abortion incidence is needed to assess the extent to which women experience unwanted pregnancies and to allocate resources for contraceptive services.

METHODS: Data for analysis came from 2,934 married women aged 15-49 who completed the 2009 Tehran Survey of Fertility. Estimated abortion rates and proportions of known pregnancies that end in abortion were calculated for all women and for demographic and socioeconomic subgroups, and descriptive data were used to examine women's contraceptive use and reasons for having an abortion.

RESULTS: Annually, married women in Tehran have about 11,500 abortions. In the year before the survey, the estimated total abortion rate was 0.16 abortion ser woman, and the annual general abortion rate was 5.5 abortions per 1,000 women; the general abortion rate peaked at 11.7 abortions among those aged 30-34. An estimated 8.7 of every 100 known pregnancies ended in abortion. The abortion rate was elevated among women who were employed or had high levels of income or education, as well as among those who reported a low level of religiosity, had two children or wanted no more. Fertility-related and socioeconomic reasons were cited by seven in 10 women who obtained an abortion. More than two-thirds of pregnancies that were terminated resulted from method failures among women who had used withdrawal, the pill or a condom.

CONCLUSIONS: Estimated abortion rates and their correlates can help policymakers and program planners identify subgroups of women who are in particular need of services and counseling to prevent unwanted pregnancy.

International Perspectives on Sexual and Reproductive Health, 2011,37(3):134-142, doi: 10.1363/3713411

In Iran, induced abortion (hereafter referred to as abortion) is strictly prohibited except when a woman's life is endangered or her fetus is diagnosed with a disease or defect that is recognized as an exception by the country's Legal Medical Organization. ${ }^{1}$ If none of these conditions is met, a woman who wants to terminate her unwanted pregnancy must resort to a clandestine and possibly unsafe abortion. Little is known about the extent of maternal mortality and the health risks associated with unsafe abortions in Iran; according to one indirect estimate, 5\% of pregnancy-related maternal deaths are due to postabortion complications. ${ }^{2}$ Many women who are admitted to the hospital for postabortion care have symptoms such as nausea, vomiting, diarrhea, lower abdominal cramps, extensive vaginal bleeding, infection or psychological distress. ${ }^{3}$

Policymakers and program planners require accurate information on abortion incidence and patterns to assess the extent to which women experience unwanted pregnancies and to determine how to allocate resources for contraceptive services and supplies. The last indirect assessment of abortion incidence in Iran relied on data collected nearly a decade ago: ${ }^{1}$ The lifetime abortion rate was estimated to be one abortion for every four married women of reproductive age, which translated to 73,000 abortions per year. The estimated rates varied widely among Iran's provinces, depending largely on levels of religiosity and use of modern contraceptives. This earlier study speculated that the abortion rate would decline if women who were using traditional methods adopted modern ones or were informed about the availability of emergency contraception. Updated information on induced abortion is needed to determine the current levels and correlates of abortion in Iran.

The present study is the first of its kind to provide direct estimates of abortion levels in Tehran for both all women and selected subgroups. It uses the most recent retrospective data to estimate the abortion rate and the proportion of known pregnancies that end in abortion for the population of married women in Tehran, to examine variations by women's demographic and socioeconomic characteristics, and to assess reported reasons for having an abortion and the contraceptive method used at the time of conception.

\section{METHODS}

Data

The main source of data was the Tehran Survey of Fertility, conducted by the author in August 2009 in the nation's capital. Modeled on a standard Demographic and Health Survey, the study questionnaire was designed to collect a wide range of data, including complete histories of live 
births, contraceptive use and abortions, as well as data on desired number of children and socioeconomic and demographic characteristics of women and their husbands. Thirty trained and experienced female interviewers collected the data during face-to-face interviews.

A three-stage stratified cluster random sampling design was used to identify married women aged 15-49 and residing in Tehran's 22 residential districts. In the first stage, enumeration areas were selected in each residential district; in the second stage, residential clusters were chosen in each selected enumeration area. In both stages, selections were based on probability proportional to population size. The sampling frame for the enumeration areas and clusters was taken from the 2006 census of Iran. In the third stage, 15 households were selected from each cluster by systematic random sampling. A table of random numbers was used to select the first household to be interviewed in each cluster. The remaining households were identified by dividing the total number of households in the selected cluster by 15 to obtain the appropriate sampling interval. One eligible woman from each selected household was then asked to participate in the survey.

To provide representative estimates of fertility-related health and demographic indicators, the study randomly selected 3,000 women. Interviews were successfully completed with 2,934 women, for a response rate of $98 \%$. Among the eligible women who were not interviewed, the principal reasons for nonresponse were failure to find them at home after repeated visits and refusal to be interviewed. The nonresponses did not bias the results, as the excluded women were from different socioeconomic and demographic subgroups. Overall, 244 women reported that they had had at least one induced abortion. These women, who reported a total of 311 abortions, were the focus of the study.

\section{Measures}

Age-specific abortion rates are the number of abortions per 1,000 women in each five-year age-group; the total abortion rate is the number of abortions that a woman aged 15-49 would be expected to have during her lifetime if she experienced the prevailing age-specific abortion rates. The annual general abortion rate refers to the number of abortions performed annually per 1,000 women aged 15-49. This study calculated these three abortion rates from the reported number of abortions in the year preceding the interview. Because of the small number of abortions in the 12 months prior to each woman's interview (19), the three rates were also calculated on the basis of the number of abortions in the five years prior to the survey (76) per 1,000 woman-years of exposure to the risk of abortion. Finally, we were not able to calculate abortion ratios comparable with recent studies ${ }^{4,5}$ because the Tehran survey did not collect complete pregnancy histories and therefore lacks data on spontaneous abortions. Instead, we calculated the proportion of known pregnancies (live births plus induced abortions) that ended in induced abortion.
The percentage distribution of abortions by women's characteristics simply reflects the distribution of women in the Tehran population, and does not necessarily show that different subgroups were more likely than others to obtain an abortion. However, the abortion rates and the proportions of pregnancies ending in abortion across subgroups do show variation in the probability that pregnant women obtained an abortion, and are therefore good measures for comparing women's abortion behavior. In addition, because no registered, external statistics on abortion in Iran are available for comparison, this study compares its estimated total abortion rate with those in 12 neighboring countries, according to the proportion of women using modern contraceptives.

This study examined associations between having an abortion and 12 demographic and socioeconomic characteristics: age at abortion, parity (number of live births), ideal number of children, desire for more children, years of schooling obtained by respondents and their husbands, women's employment status, importance of religion (ranging from "very important" to "not at all"), ethnicity of respondents and their husbands, income level (measured indirectly by household monthly expenditure) and residential district (categorized as northern, central or southern on the basis of a cluster analysis of couples' schooling and household expenditure). Residents in the northern districts of Tehran are generally wealthier and more educated, and hold more modern attitudes regarding family formation and childbearing, while those in southern districts generally have lower socioeconomic status and hold traditional attitudes toward family matters.

Women were also asked the most important reason for having had an abortion in the five years preceding the survey; 71 respondents answered this question. Five women had had two abortions in this period, yielding a total of 76 abortions; they gave a reason for each abortion. Reasons were grouped into three categories: health-related (risk to maternal health or to fetal health, bleeding during pregnancy), fertility-related (to limit births, space births or postpone childbearing) and socioeconomic (economic difficulty, spousal relationship problem). To address the possibility of social desirability bias in these responses, 666 respondents who knew a neighbor, friend or relative who had had an abortion in the past year were asked the woman's main reason for having the abortion.

\section{RESULTS}

\section{Abortion and Contraceptive Use}

No respondents aged 15-19 reported having had an abortion in the year preceding the survey; the abortion rate was highest among women aged 30-34 (11.7 per 1,000 women), was 9.8 per 1,000 among those aged 35-39 and declined dramatically among older women (Table 1, page 136). Thus, the age-specific abortion rates show an inverted U-shaped pattern (Figure 1, page 136). Furthermore, as shown in Figure 1, the level of abortion was lower than that of fertility among women younger than 30 . In gener- 


\begin{tabular}{|c|c|c|}
\hline Measure & 1 year & 5 years \\
\hline \multicolumn{3}{|l|}{ Age-specific abortion rate (per 1,000 women) } \\
\hline $15-19$ & 0.0 & 0.0 \\
\hline $20-24$ & 1.5 & 5.1 \\
\hline $25-29$ & 4.7 & 4.9 \\
\hline 30-34 & 11.7 & 9.5 \\
\hline $35-39$ & 9.8 & 7.0 \\
\hline $40-44$ & 2.0 & 0.8 \\
\hline $45-49$ & 2.1 & 1.8 \\
\hline Total abortion rate (per woman) & 0.16 & 0.15 \\
\hline Annual general abortion rate (per 1,000 women) & 5.5 & 5.2 \\
\hline Abortions as \% of known pregnancies & 8.7 & 7.5 \\
\hline Mean age at abortion & 33.5 & 32.0 \\
\hline Median age at abortion & 33.0 & 32.0 \\
\hline Annual no. of abortions & 11,543 & na \\
\hline
\end{tabular}

Notes: The proportion of known pregnancies that end in abortion and the mean age at abortion were estimated for married women aged 20-49; other figures were estimated for all women aged 15-49.na=not applicable.

al, the age-specific rates for the five-year period prior to the survey were similar to those for the year before the survey.

The total abortion rate for the year prior to the survey was estimated to be 0.16 abortions per married woman aged 15-49. Hence, on average, one of every six women of reproductive age will have an abortion in their lifetime if current age-specific abortion rates remain unchanged. Moreover, the estimated general abortion rate of 5.5 indicates that about six abortions were obtained annually per 1,000 women aged 20-49. According to the 2006 Iran census, the number of women in this age-group living in Tehran was 2,098,790. ${ }^{6}$ Therefore, this study estimates that women in Tehran obtain 11,543 abortions annually.

The estimated total abortion rate for women in Tehran

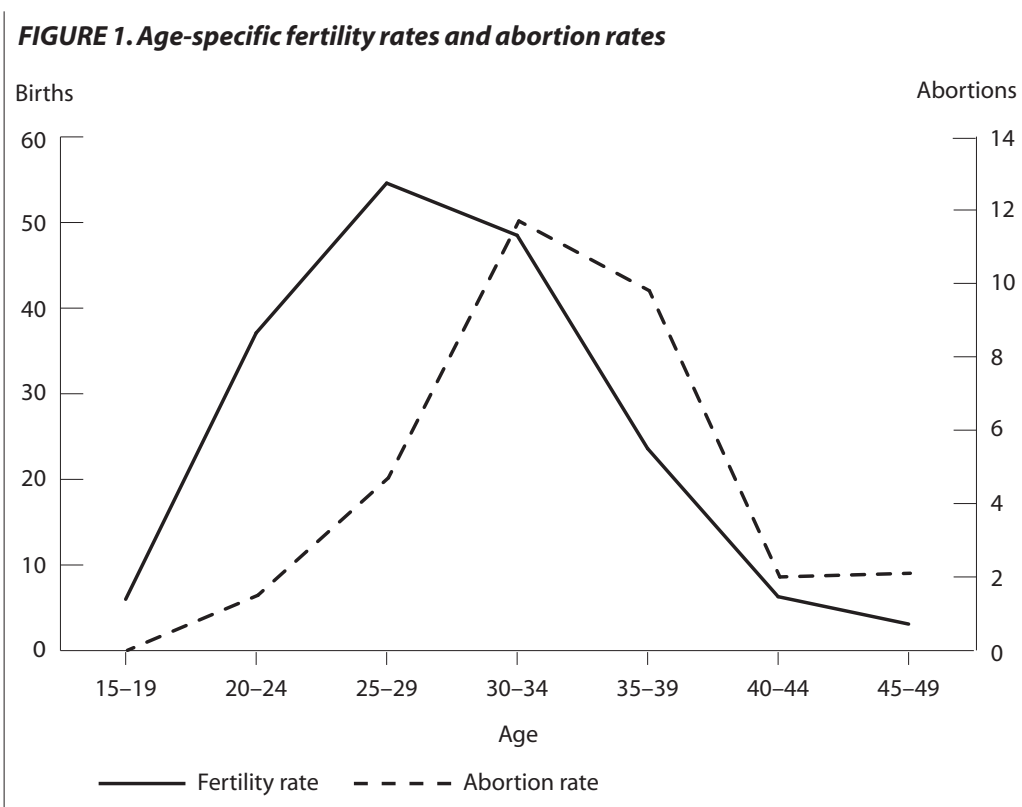

Note: Age-specific fertility and abortion rates are based on fertility and abortions, respectively, in the year preceding the survey; both rates are per 1,000 women in a given age-group. appears to be low when compared with the rates in selected neighboring countries in Central Asia and Eastern 'Europe, which range from 0.3 abortions per woman in Turkey to 3.7 in Georgia (Figure 2). Though abortion underreporting is one possible reason for the low estimated rate for Tehran, the roles of contraceptive use, intended fertility and the probability of recourse to abortion should be taken into account. According to Bongaarts and Westoff, 7 variation in abortion rates among countries is accounted for largely by these three factors.

In the present study, $85 \%$ of married women reported using a contraceptive method at the time of the survey; 54\% used a modern method and 31\% used a traditional one. The most commonly used method was withdrawal (30\%); fewer than 1\% of women used abstinence. Among modern methods, the condom was the most widely used ( $16 \%$ ), followed by the IUD (13\%), female sterilization (11\%), the pill (9\%), male sterilization (6\%) and the implant $(<1 \%)$. Withdrawal was relied on by relatively equal proportions of women across age-groups, while women with one child were twice as likely as those with at least three children to use the method (not shown). ${ }^{8}$ Compared with the countries in Figure 2, Tehran has a lower abortion rate and higher use of modern methods. In these countries and Tehran, total abortion rates were strongly but negatively associated with the use of modern methods: The rates decreased as the use of modern contraceptives increased $(r=-0.87)$. However, the association between the use of traditional methods and abortion rates was positive (r=0.30; not shown).

An estimated 8.7 of every 100 known pregnancies ended in abortion in the year preceding the survey. The proportion for the preceding five-year period was slightly lower ( 7.5 of every 100 pregnancies).

\section{Correlates of Abortion Incidence}

In one previous worldwide study, a woman's decision to obtain an abortion was associated with a number of demographic and socioeconomic characteristics, ${ }^{9}$ which influence the decision mainly via three factors: the probability of having an abortion in the event of contraceptive failure, fertility preferences and effective method use. ${ }^{7}$ Furthermore, these characteristics are assumed to influence a woman's decision either by themselves or as indicators of a woman's social or economic situation. For instance, the likelihood of having an abortion was elevated among women who had high levels of education, as well as among those who had a large number of children. ${ }^{9}$ Table 2 (page 138) presents the percentage distribution of abortions and the estimated abortion rates and proportions of pregnancies ending in abortion across subgroups of women who had had at least one abortion in the five-year period preceding the survey.

- Age at abortion. The highest proportions of abortions occurred among women aged $30-34$ and 35 or older (37\% and $32 \%$, respectively). The proportion of pregnancies ending in abortion according to age-group followed a near- 
ly monotonically increasing pattern: It was zero among teenagers and rose to 20 of every 100 pregnancies among women aged 35 or older. Variation in the abortion rate by age at abortion was similar to that in the proportion of pregnancies ending in abortion, except that the abortion rate fell for the oldest age-group.

- Parity. The distribution of abortions varied sharply by parity. Childless women obtained 9\% of all abortions, while those who had two children at the time of the interview obtained 53\%. Although the abortion rate followed a similar pattern, the proportion of pregnancies ending in abortion did not: Nulliparous women and those with two children terminated $11 \%$ of their pregnancies, whereas the proportions terminated by women with one child or at least three were lower (5-6\%).

- Fertility preference and desire. Nearly six in 10 abortions were obtained by women who wanted two children, and one in three abortions were reported by those who wanted a single child. Nonetheless, our abortion measures showed an inverse relationship between abortion and the ideal number of children: The abortion rate and the proportion of known pregnancies ending in abortion were highest (6.5 per 1,000 women and 8.6 of every 100 pregnancies, respectively) among women who wanted only one child, and both fell steadily as the desired number of children increased. Similarly, women who wanted no more children had the highest abortion rate and proportion of pregnancies ending in abortion.

-Education. The percentage distribution of abortions by educational attainment largely reflected the distribution of women and their husbands by schooling. However, the abortion rate rose monotonically as education level increased, with a sharp rise among women whose husband had some postsecondary education. The proportion of known pregnancies ending in abortion by women's schooling showed an inverted U-shaped relationship, in which the incidence of abortion reached a peak among women who had some secondary schooling (8.6 of every 100 pregnancies). In contrast, the proportion was 7.5 of every 100 pregnancies among women whose husband had only primary schooling, fell to the lowest level among those whose husband had 6-12 years of schooling (6.7 of every 100) and reached a high of 9.1 of every 100 pregnancies among those whose husband had postsecondary education.

- Employment. The vast majority of abortions were obtained by unemployed women. However, the proportion of pregnancies ending in abortion was higher among the employed than the unemployed ( 8.7 of every 100 pregnancies vs. 7.3 of every 100). Similar levels have been observed in the whole population of Iran. ${ }^{10}$ The abortion rate was also higher among employed women.

- Religiosity. Most abortions were obtained by women who said that religion was very or somewhat important in their life. The proportion of pregnancies ending in abortion, however, showed an inverse relationship between incidence of abortion and religiosity. The proportion ranged
FIGURE 2. Relationship between the total abortion rate and the percentage of women using modern contraceptives, in selected countries and Tehran

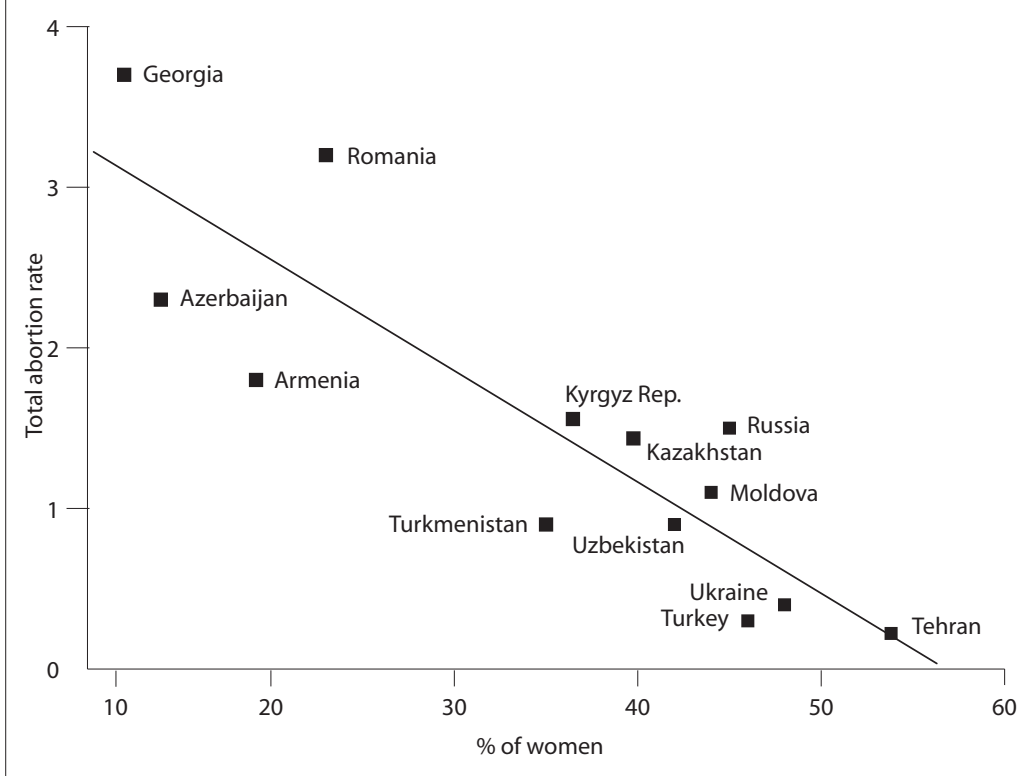

Notes: Total abortion rate $=3.8-0.07 \times$ rate of modern contraceptive use; $R^{2}=0.75(p<.001)$. Russian data are for three cities. Contraceptive data for Tehran, Turkey, Azerbaijan, Armenia, Moldova and the Ukraine are based on reports from currently married women aged 15-49; these data for other countries are based on reports from all women aged 15-44. Sources: Armenia-National Statistical Service of Armenia (NSS), Ministry of Health of Armenia (MOH) and ORC Macro, Armenia Demographic and Health Survey, 2005, Calverton, MD, USA:NSS, MOH and ORC Macro, 2006. Azerbaijan - State Statistical Committee of Azerbaijan (SSC) and Macro International, Azerbaijan Demographic and Health Survey, 2006, Calverton, MD, USA: SSC and Macro International, 2008. Moldova-National Scientific and Applied Center for Preventive Medicine of Moldova (NSACPM) and ORC Macro, Moldova Demographic and Health Survey, 2005, Calverton, MD, USA: NSACPM and ORC Macro, 2006. Turkey-Hacettepe University Institute of Population Studies (IPS), Turkey Demographic and Health Survey, 2008, Ankara, Turkey:IPS, 2009.Ukraine-Ukrainian Center for Social Reforms (UCSR) et al., Ukraine Demographic and Health Survey, 2007,Calverton, MD, USA:UCSR and Macro International, 2008. Other countries—reference 19.

from 6.7 of every 100 pregnancies among women who believed religion was very important to 10.8 of every 100 pregnancies among those who viewed religion as not too or not at all important. The estimated abortion rate also increased as women's level of religiosity declined.

-Ethnicity. The distribution of abortions and the proportion of pregnancies ending in abortion varied substantially by ethnicity. Though the patterns of abortion and ethnicity of women and their husbands were similar, variation in the abortion rate and the proportion of pregnancies ending in abortion by husband's ethnicity was stronger. Gilak and Mazandarani women accounted for only 9\% of known estimated abortions, but had the highest proportion of pregnancies ending in abortion of all ethnicities (10.4\%). Similarly, women whose husband was Gilak or Mazandarani accounted for $13 \%$ of abortions, but they had the highest proportion of pregnancies ending in abortion ( 16.4 of every 100 known pregnancies) and the highest abortion rate ( 11.5 abortions per 1,000 women). Their high abortion rate can be explained partly by the fact that women from these ethnic groups have the highest level of withdrawal use in Iran. ${ }^{11}$

- Household expenditure. The percentage distribution of abortions by household expenditure indicated that nearly two-thirds of abortions were obtained by women in the third and fourth highest income quartiles. The proportion 
TABLE 2. Selected measures of abortions and pregnancies among women who have had at least one abortion in the five years preceding the survey, by various characteristics

$\begin{array}{llllll}\text { Characteristic } & \begin{array}{l}\text { \% distribution } \\ \text { of abortions }\end{array} & \begin{array}{l}\% \text { of } \\ \text { pregnancies } \\ \text { aborted }\end{array} & \begin{array}{l}\text { No.of } \\ \text { abortions }\end{array} & \begin{array}{l}\text { No.of known } \\ \text { pregnancies }\end{array} & \begin{array}{l}\text { Abortion } \\ \text { rate }\end{array}\end{array}$

\begin{tabular}{llclll}
\hline All & 100.0 & 7.5 & 76 & 1,009 & 5.2
\end{tabular}

Age at abortion

$<20$

20-24

$25-29$

$30-34$

$\geq 35$

0.0

13.2

18.4

36.8

31.6

$\begin{array}{rr}0.0 & 0 \\ 4.3 & 10 \\ 3.8 & 14 \\ 11.1 & 28 \\ 20.0 & 24\end{array}$

0.0

10

14

20.0

24

230

368

253

120

No. of live births

0

1

2

9.2

26.4

52.6

11.8

$10.6^{*}$

4.7

10.6

6.3

Ideal no. of children

1

2

$\geq 3$

34.2

57.9

7.9

8.6

7.1

6.7

7

20

40

66

423

377

143

5.1

7.2

2.6

6.5

$\begin{array}{ll}303 & 6.5 \\ 617 & 5.3\end{array}$

$89 \quad 2.6$

Desire for more children

Yes

17.0

No

83.0

5.9

8.0

13

222

4.3

Women's yrs. of schooling

$<6$

6-11

7.9

21.1

12

$\geq 13$

27.6

Husbands' yrs. of schooling

$<6$

6-11

9.2

12

$\geq 13$

22.4

30.2
38.2

Women's employment status

Unemployed $\quad 82.9$

Employed

17.1

Importance of religion

Very important $\quad 51.3$

Somewhat important $\quad 38.2$

Not too important/not at all10.5

Woman's ethnicity

Fars

Turk

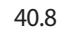

39.5

Gilak/Mazandarani

9.2

Lur

Other (Kurd/Arab/Baluch/

Turkman)

3.9

6.1
8.6

8.6
7.7

7.1

7.5

6.7

6.7

9.1

7.3

8.7

6.7

8.2

10.8

63

787

5.4

3.0

4.9

5.6

6.1

Husband's ethnicity

Fars $\quad 42.1$

Turk $\quad 36.8$

Gilak/Mazandarani $\quad 13.2$

Lur

Other (Kurd/Arab/Baluch/

Turkman)

2.6

6.5

8.5

10.4

7.8

6.3

6.4

8.5

16.4

5.9

3.8

Quartile of household monthly expenditure (\$US)

First (30-350)

Second (351-500)

Third (501-800)

Fourth (>800)

17.1

19.7

36.8

4.1

3.0

11.3

11.7

15

28

20

317
248

171

4.0

4.5

4.7

6.9

5.1

5.7

4.3

6.2

Residential district

Northern

Central

$29.0 \quad 10.2$

43.4

27.6

10.2
7.9

5.6

22

21

216

416

377

5.9

4.7

*The denominator for zero parity includes 59 current pregnancies and seven induced abortions. Note: The abor-

tion rates and proportions are based on the five years before the survey.
TABLE 3. Percentage distribution of abortions in the five years preceding the survey, by women's most important reason for having an abortion

Reason

$\%$

$(\mathrm{N}=76)$

Fertility-related $\quad 47.3$

To limit births

To space next birth

35.5

To postpone childbearing*

5.2

6.6

Health-related

31.6

Risk to fetal health

Risk to maternal health

19.7

6.6

Bleeding during pregnancy

5.3

Socioeconomic

21.1

Economic difficulty

18.5

Spousal relationship problem

2.6

Total

100.0

*Includes mainly abortions of pregnancies that occurred before or during the

engagement period.

of pregnancies ending in abortion and the abortion rate reflect this pattern: The proportion rose from 4.1 of every 100 pregnancies among women in the first quartile to 11.7 of every 100 among those in the fourth quartile, and the corresponding rate increased from 3.5 to 6.4 abortions per 1,000 women.

- Residential district. Women in the central and northern districts obtained $43 \%$ and $29 \%$ of abortions, respectively, while those in the southern districts obtained $28 \%$. The estimated proportions of pregnancies ending in abortion and abortion rates showed the expected pattern: The proportion in the central district was 7.9 of every 100 pregnancies, compared with 10.2 in the northern district and 5.6 in the southern district. The corresponding abortion rates were 5.1, 5.9 and 4.7 abortions per 1,000 women, respectively.

TABLE 4. Percentage distribution of respondents who knew a woman who had had an abortion in the year preceding the survey, by the woman's most important reason for having an abortion

Reason

$\%$

$(\mathrm{N}=666)$

Fertility-related

Neither spouse wanted more children

Husband did not want more children

61.3

To space next birth

To postpone childbearing*

3.5
10.0

4.7

Health-related

Risk to fetal health

19.3

Risk to maternal health

11.5

Socioeconomic

15.1

Economic difficulty

Spousal relationship problem

9.8

Gender preference

Don't know

4.3

Total

100.0

*Includes mainly abortions of pregnancies that occurred before or during the engagement period. 


\begin{tabular}{|c|c|}
\hline Method & $\%$ \\
\hline None & 15.8 \\
\hline Any traditional & 52.6 \\
\hline Withdrawal & 44.7 \\
\hline Rhythm & 7.9 \\
\hline Any modern & 31.6 \\
\hline Pill & 15.8 \\
\hline Condom & 10.5 \\
\hline IUD & 5.3 \\
\hline Total & 100.0 \\
\hline
\end{tabular}

\section{Reasons for Having an Abortion}

- Fertility-related. Consistent with findings from 27 countries, ${ }^{12}$ the most common reasons given by women who reported having had an abortion in the five years preceding the Tehran survey were fertility-related (47\%-Table 3). The most frequently cited reason was to limit births (36\%); women cited spacing births and postponing childbearing $5 \%$ and $7 \%$ of the time, respectively. The pregnancies terminated for the latter reason mainly occurred before or during engagement.

Among the 666 women who reported on why a neighbor, friend or relative had had an abortion in the past year, 61\% cited a fertility-related reason (Table 4): Forty-three percent said that neither the husband nor the wife had wanted to have more children, $4 \%$ said the husband had wanted no more, and $10 \%$ and $5 \%$, respectively, said the main reason was to space births or postpone the initiation of childbearing..

- Health-related. For 32\% of abortions performed in the past five years, a health-related reason was considered the most important: Risk to fetal or maternal health was cited $20 \%$ and $7 \%$ of the time, respectively, and vaginal bleeding during pregnancy in 5\% of cases. Among respondents who knew a woman who had had an abortion in the last year, only $19 \%$ cited the reasons related to fetal or maternal health (12\% and $8 \%$, respectively).

- Socioeconomic. Twenty-one percent of abortions performed in the five years preceding the survey were undertaken for a socioeconomic reason: 19\% for economic difficulty and 3\% for a spousal relationship problem (divorce, separation or a partner's drug addiction). Fifteen percent of respondents who knew another woman who had had an abortion in the previous year said the main reason for them undergoing the procedure was a socioeconomic issue.

\section{Contraceptive Failure and Abortion}

Overall, 84\% of abortions in the five years preceding the survey resulted from contraceptive failures; women who obtained the other $16 \%$ of abortions were not using a method when they became pregnant (Table 5). Among all abortions, withdrawal had been used in $45 \%$ of cases, the pill in $16 \%$ and a condom in $11 \%$.

\section{DISCUSSION}

This study provides new estimates of abortion incidence at the population and subgroup levels in Tehran, where about 15\% of Iran's population resides. This is the first study to analyze retrospective data collected from a survey of married women aged 15-49.

The estimated abortion rates indicate that more than 11,500 abortions are performed annually in Tehran, and 9\% of known pregnancies end in abortion. In contrast with women in most countries, where the incidence of abortion is highest among women in their $20 \mathrm{~s},{ }^{9}$ the current estimates reveal that women in Tehran are most likely to obtain an abortion in their 30s. Moreover, the incidence of abortion among married 15-19-year-olds appears to be zero, which may be largely due to a strong desire for childbearing early in marriage. However, respondents may have underreported abortions that were performed before marriage or during the engagement period. Taken together, the high mean age at abortion among married women in Tehran can be attributed to a rise in the age at marriage and a strong preference to stop or space childbearing in the mid-30s.

Unlike the case in many countries in Western Europe and North and South America, where U-shaped relationships between the proportion of pregnancies ending in abortion and age at abortion show high proportions among adolescents, ${ }^{9}$ in Tehran the proportion was lowest among married adolescents. A similar pattern has been observed among married women in some Asian countries, especially those in Central Asia that have a Muslim majority population. ${ }^{9}$ Possible reasons for this difference may be higher levels of nonmarital sexual activity and unwanted pregnancy among women in non-Asian countries, and a greater motivation for postponing childbearing until they complete their education or secure a job.

This study found that $9 \%$ of abortions were obtained by nulliparous women, including those who got pregnant before or during their engagement, or after getting married. It is likely that many other women who got pregnant during the engagement period and did not report their abortions either proceeded to get married quickly or terminated their unplanned pregnancy by seeking a clandestine abortion. Such abortions are usually underreported in demographic surveys, because nonmarital pregnancies are not socially or religiously acceptable. In addition, women who were childless or had two children had the highest proportions of pregnancies ending in abortion, suggesting that in Tehran, women have abortions largely to limit or to space births, or to delay the onset of childbearing.

The relationship between abortion and education level varies across countries in the region: A positive correlation between abortion and education has been observed in Turkey, Armenia, Azerbaijan and Turkmenistan, whereas in other Central Asian and Eastern European countries, less-educated women appear more likely to seek abortions. ${ }^{13,14}$ Although the present study found a positive relationship between abortion rates and couples' increasing 
education level, the proportion of pregnancies ending in abortion by education revealed a more complex relationship. The inverted U-shaped pattern for women's schooling suggests that better-educated women and women with primary or no schooling may have stronger motivations to prevent unplanned births and hence have higher contraceptive use. By contrast, the U-shaped pattern found for husband's educational attainment may indicate that both less- and better-educated husbands play a greater role than those with an intermediate level of education in decision making regarding fertility control and abortion. Indeed, the high proportion of pregnancies ending in abortion among women whose husband had little education may suggest that the motivation for stopping childbearing is stronger than the motivation for spacing births or delaying family formation. Better-educated husbands may encourage their wife to have an abortion to achieve a smaller family. This scenario is consistent with evidence showing that more highly educated husbands in Iran mostly use male-based contraceptive methods, especially withdrawal, to limit childbearing. ${ }^{11}$ Although a qualitative study ${ }^{15}$ found spousal cooperation in choosing male methods to avoid the side effects of modern female methods, the present findings support the speculation that an educated husband in Tehran often encourages his wife to seek an abortion in the event of an unintended pregnancy. Further research is needed to examine this important topic.

The results on ethnicity and use of abortion also suggest that husbands play an important role in decision making: The proportion of pregnancies ending in abortion and the abortion rate were greater among women whose husbands were Gilak or Mazandarani. The widespread use of withdrawal may partly explain this elevated use of abortion. According to another study, ${ }^{1}$ the Tehran population is moderately religious, and the current research found an inverse relationship between abortion and the degree of religiosity.

The findings on health-related reasons for getting an abortion should be looked at with some caution in the context of Iran, where abortion is severely restricted. An important area of uncertainty is whether the potential health risk to the mother or the fetus has been identified by only the woman herself or-as required by law-by three expert physicians and a legal physician, appointed by the judiciary. Since serious threats to maternal or fetal health are legal reasons for obtaining an abortion in Iran, many women may report one of these because they are socially acceptable and provide a legal or moral justification for what otherwise may be an illegal abortion. Furthermore, if one assumes that abortions obtained for reasons not related to health are illegal, respondents' reports of their reasons would imply that $70-80 \%$ of abortions in Tehran were most likely performed illegally and clandestinely.

Despite the fact that a large proportion of abortions were preceded by failures in withdrawal use, it should be

*Among pregnant women interviewed in 2009 , only $10 \%$ reported that their pregnancies were "unwanted." noted that a greater rate of abortion associated with such failures would have been expected if married women had not had access to emergency contraceptive pills. Withdrawal remains a popular method among many married women, and having wide access to free emergency contraceptive pills-supplied by the Ministry of Health through health centers and clinics ${ }^{16}$-enables women to prevent many unwanted pregnancies. Generally, the study's findings on the relationship between contraception and abortion support the view that access to and use of effective modern contraceptives, including emergency contraceptive pills in the event of method failure, may decrease the demand for and reliance on abortion among married women living in Tehran.

Stabilized fertility levels and preferences may also be related to the low incidence of abortion in Tehran. The relationship between abortion and contraceptive use has been shown to be mediated by the stage of a country's fertility transition; that is, after fertility levels stabilize-normally when the fertility transition is completed-contraceptive use continues to increase and the abortion rate falls. ${ }^{17}$ Tehran represents a clear-cut example of this, as its total fertility rate, which was 1.3 children per woman in 2000, remained below replacement level in 2009 ( 1.6 children). Over this period, contraceptive prevalence has been the most important determinant of fertility, accounting for 63-69\% of the below-replacement fertility rates. ${ }^{8,18}$ In contrast, the abortion rate was estimated to be responsible for only $3 \%$ of the corresponding reduction in fertility. ${ }^{18}$

Given that access to legal abortion in Tehran is severely restricted, and hence recourse to illegal abortion entails significant cost and risk, and also given the high prevalence of contraceptive use and easy access to free emergency contraceptive pills, one would expect fewer unwanted pregnancies* and a lower abortion rate. Nonetheless, the actual abortion rate in Tehran is likely higher than that estimated by the current study, as abortion underreporting in surveys has been well documented. ${ }^{19-21}$

\section{Strengths and Limitations}

The abortion rates and the proportions of pregnancies ending in abortion calculated for socioeconomic and demographic subgroups of women were based on abortions reported in the five years preceding the survey, in an effort to minimize bias from retrospective reporting. Limiting analysis to abortions in this period also lessens the possibility that women's characteristics may have changed since the reported abortions. However, because information on characteristics (except age at abortion) was collected at the time of interview, the possibility of some inconsistency must be considered when interpreting findings, especially for fertility preference and desire, which often change over time. In addition, it was assumed that abortion underreporting did not vary by women's characteristics.

Survey-based abortion estimates have been considered to be incomplete, as some women do not report their abortions, especially in face-to-face interviews. ${ }^{19}$ Several stud- 
ies have indicated that, on average, only half of induced abortions performed in the United States and other countries were reported by women during face-to-face interviews in representative surveys. ${ }^{19-21}$ These studies also showed that abortion underreporting varied substantially across subgroups of women.

\section{Conclusions}

This study helps identify subgroups of women who are in particular need of services and counseling to prevent unintended pregnancy. Clearly, any shifts in the country's current population policy and family planning program may affect the incidence of abortion in Iran, given the strong motivation of couples to achieve a small family size. Currently, Iran's government has identified the country's below-replacement total fertility rate $(1.8)^{6}$ as a threat to future development, and has recommended a doubling of the nation's population. Should this political debate result in a new population policy-one in which family planning services and counseling are limited-it is likely that the incidence of unsafe, clandestine abortion will increase.

\section{REFERENCES}

1. Erfani A and McQuillan K, Rates of induced abortion in Iran: the roles of contraceptive use and religiosity, Studies in Family Planning, 2008, 39(2):111-122.

2. Naghavi M, Estimate of Iran's Maternal Mortality Due to Pregnancies and Deliveries, Using Reproductive Age Mortality Survey (RAMOS), Tehran, Iran: Ministry of Health and Medical Education, 1996 (in Persian).

3. Mohammad-Zadeh $\mathrm{F}$ and Fallahian $\mathrm{M}$, Induced abortion in Taleghani Hospital: 2001-2002, Journal of Legal Medicine, 2004, 9(32): 190-193 (in Persian).

4. Sedgh $\mathrm{G}$ et al., Induced abortion: estimated rates and trends worldwide, Lancet, 2007, 370(9595):1338-1345.

5. Singh S et al., Abortion Worldwide: A Decade of Uneven Progress, New York: Guttmacher Institute, 2009.

6. Statistical Centre of Iran, The Results of National Population and Housing Census, 2006, Tehran: Statistical Centre of Iran, 2008 (in Persian).

7. Bongaarts $J$ and Westoff $C F$, The potential role of contraception in reducing abortion, Studies in Family Planning, 2000, 31(3):193-202.

8. Erfani A, Tehran Survey of Fertility, 2009: Final Report, Tehran, Iran: Population Studies and Research Center in Asia and the Pacific, 2010.

9. Bankole A, Singh S and Haas T, Characteristics of women who obtain induced abortion: a worldwide review, International Family Planning Perspectives, 1999, 25(2):68-77.

10. Erfani A, Abortion in Iran: What do we know? London, Canada: Population Studies Center, University of Western Ontario, 2008, $<$ http://sociology.uwo.ca/popstudies/dp/dp08-01.pdf>, accessed Aug. 16, 2010.

11. Erfani A, Factors associated with the use of withdrawal in Iran: Do fertility intentions matter? Journal of Comparative Family Studies, 2011 (forthcoming).

12. Bankole A, Singh S and Haas T, Reasons why women have induced abortions: evidence from 27 countries, International Family Planning Perspectives, 1998, 24(3):117-127 \& 152.

13. Westoff CF, Recent trends in abortion and contraception in 12 countries, DHS Analytical Studies, Calverton, MD, USA: ORC Macro, 2005, No. 8.

14. Tezcan S, Ergöçmen B and Tunçkanat FH, Abortions and still- births, in: Turkish Demographic and Health Survey, 2008, Ankara, Turkey: Hacettepe University Institute of Population Studies, 2009, pp. 96-106.

15. Rahnama $P$ et al., Why Iranian married women use withdrawal in stead of oral contraceptives? A qualitative study from Iran, BMC Public Health, 2010, Vol. 10, Art. 289, <http://www.biomedcentral.com/ 1471-2458/10/289\#>, accessed June 22, 2011.

16. Ministry of Health and Medical Education, The Instructions for the Use of Modern Contraceptive Methods in the Islamic Republic of Iran, Tehran, Iran: Ministry of Health and Medical Education, Office of Population and Family Planning, 2009 (in Persian).

17. Marston C and Cleland J, Relationships between contraception and abortion: a review of the evidence, International Family Planning Perspectives, 2003, 29(1):6-13.

18. Erfani A and McQuillan K, Rapid fertility decline in Iran: analysis of intermediate variables, Journal of Biosocial Science, 2008, 40(3): 459-478.

19. Rossier C, Estimating induced abortion rates: a review, Studies in Family Planning, 2003, 34(2):87-102.

20. Jones RK and Kost $\mathrm{K}$, Underreporting of induced and spontaneous abortion in the United States: an analysis of the 2002 National Survey of Family Growth, Studies in Family Planning, 2007, 38(3): 187-197.

21. Fu $\mathrm{H}$ et al., Measuring the extent of abortion underreporting in the 1995 National Survey of Family Growth, Family Planning Perspectives, 1998, 30(3):128-133 \& 138.

\section{RESUMEN}

Contexto: El aborto inducido está severamente restringido en Irán, y muchas mujeres con embarazos no deseados se recurren a abortos clandestinos e inseguros. Se necesita información precisa sobre la incidencia del aborto para evaluar el grado en el que las mujeres tienen embarazos no deseados y para asignar recursos a los servicios anticonceptivos.

Métodos: Los datos para el análisis provinieron de 2,934 mujeres casadas en edades de 15-49 que completaron la Encuesta sobre Fecundidad de Teherán de 2009. Se estimaron las tasas de aborto y la proporción de embarazos conocidos que terminan en aborto inducido, para todas las mujeres y para subgrupos demográficos y socioeconómicos; y se usaron datos descriptivos para examinar el uso de anticonceptivos por parte de las mujeres y las razones por las cuales tuvieron un aborto. Resultados: Cada año, las mujeres casadas en Teherán tienen cerca de 11,500 abortos. En el año antes de la encuesta, la tasa estimada de aborto fue de 0.16 abortos por mujer; y la tasa general de aborto fue de 5.5 abortos por 1,000 mujeres. La tasa general de aborto más alta llegó a 11.7 abortos por 1,000 mujeres de 30-34 años. En Teherán, hubo 8.7 abortos por cada 100 embarazos conocidos. Según los datos demográficos y socioeconómicos, la tasa de aborto fue elevada en mujeres que estaban empleadas o que tenían altos niveles de ingreso o educación, así como en las que reportaron un bajo nivel de religiosidad, tenían dos hijos o no deseaban más hijos. Siete de cada 10 mujeres que tuvieron un aborto citaron razones socioeconómicas o relacionadas con la fecundidad. Más de dos tercios de los embarazos que fueron interrumpidos habian resultado de fallas del método en mujeres que habían usado el método del retiro, la píldora o el condón.

Conclusiones: Las tasas estimadas de aborto y sus correlaciones pueden ayudar a los encargados de formular políticas $y$ 
planificadores de programa a identificar los subgrupos de mujeres que tienen especial necesidad de servicios y de consejería para prevenir el embarazo no deseado.

\section{RÉSUMÉ}

Contexte: L'avortement est strictement limité en Iran, où de nombreuses femmes confrontées à une grossesse non desirée recourent aux procédures clandestines non médicalisées. Une information précise sur l'incidence de l'avortement serait utile à l'évaluation de celle des grossesses non desirées et à l'allocation de ressources à la contraception.

Méthodes: Les données soumises à l'analyse sont celles relatives à 2.934 femmes mariées ayant participé à l'Enquête de Téhéran sur la fécondité. Le taux et le pourcentage de grossesses connue ayant aboutí sur une IVG ont été estimés pour toutes les femmes et tous les sous-groupes démographiques et socioéconomiques. L'examen de la pratique contraceptive des femmes et de leurs raisons d'avortement repose sur des données descriptives. Résultats: Quelque 11.500 IVG avaient été pratiquées parmi les femmes mariées de Téhéran. Le taux d'avortement total estimé est de 0,16 par femme, pour un taux général annuel de 5,5 pour 1.000 femmes. Ce taux culmine à 11,7 dans la tranche des
30 à 34 ans. Sur 100 grossesses connues, 8,7 avaient été interrompues. Le taux d'avortement est élevé parmi les femmes employées ou à haut niveau de revenu ou d'éducation, ainsi que parmi celles ayant déclaré un faible niveau de religiosité, avoir deux enfants ou ne plus en désirer. Sept femmes sur 10 ayant recouru à l'avortement invoquent des raisons de fécondité et socioéconomiques. Plus de deux tiers des grossesses non désirées interrompues étaient le résultat d'un échec de méthode parmi les femmes qui avaient utilisé le retrait, la pilule ou le préservatif.

Conclusions: Les taux d'avortement estimés et leurs corrélats peuvent aider les décideurs politiques et les planificateurs de programmes à identifier les sous-groupes de femmes qui présentent un besoin particulier de services et conseil pour éviter une grossesse non planifiée.

\section{Acknowledgments}

The 2009 Tehran Survey of Fertility was supported by the Population Studies and Research Center for Asia and the Pacific (Tehran, Iran) and Nipissing University.

Author contact:amire@nipissingu.ca 